\title{
Redução de Danos em Florianópolis-SC: uma política estratégica de prevenção e cuidado à saúde
}

\author{
Harm reduction in Florianópolis-SC: a strategic policy for prevention and health care
}

Reducción de deterioros en Florianópolis-SC: una política estratégica de prevención y cuidado de la salud

Isabel Cristina Alves Maliska ${ }^{1}$, Maria Itayra Padilha², Selma Regina Andrade ${ }^{3}$

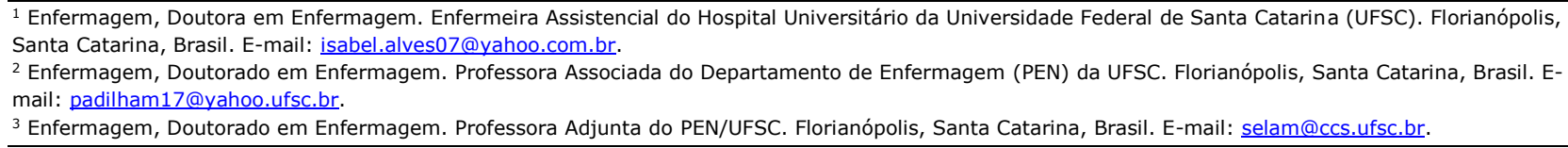

\section{RESUMO}

Estudo descritivo qualitativo com perspectiva sócio-histórica, que analisa como a política de Redução de Danos se desenvolveu enquanto estratégia de prevenção e cuidado do HIV/AIDS entre os usuários de drogas injetáveis no município de Florianópolis-SC. Foram realizadas entrevistas utilizando a técnica de História Oral Temática. Os sujeitos do estudo foram dez profissionais de saúde que exerceram atividades de assistência e/ou gestão vinculadas as DST/AIDS no período do estudo (1993-2010). Para tratamento dos dados utilizou-se análise de conteúdo, chegando a duas categorias: A implantação do Projeto de Redução de Danos em Florianópolis; e O reconhecimento da Redução de Danos como política estratégica de prevenção ao HIV e outras situações de vulnerabilidade. Como resultados, destaca-se neste município aspectos desta política inclusiva e inovadora no cuidado em saúde, ao colocar em prática princípios substantivos do SUS entre usuários de drogas, gerando novas possibilidades de prevenção e cuidado entre esta população.

Descritores: Síndrome de Imunodeficiência Adquirida; Usuários de Drogas; Redução do Dano.

\section{ABSTRACT}

This descriptive qualitative study was performed with a socio-historical perspective, and analyzes how the Harm Reduction policy was developed as a strategy for HIV/AIDS prevention and care among injectable drug users in the municipality of Florianópolis-Santa Catarina state. Interviews were performed using the Thematic Oral History technique. The subjects were ten health care professionals working with health care and/or management activities related to STD/AIDS during the period of the study (1993-2010). Content analysis was used, resulting in two categories: The implementation of the Harm Reduction Project in Florianópolis; and Recognizing Harm Reduction as a strategic policy for the prevention of HIV and other situations of vulnerability. The main results, in the referred municipality, were aspects of this inclusive and innovative policy in health care, by practicing central principles of the Unified Health System (SUS) among drug users, thus generating new possibilities for the prevention and care among this population.

Descriptors: Acquired Immunodeficiency Syndrome; Drug Users; Harm Reduction

\section{RESUMEN}

Estudio descriptivo, cualitativo, con perspectiva socio-histórica, analizando cómo la política de Reducción de Deterioros se desarrolló en carácter de estrategia de prevención y cuidado del HIV/SIDA entre usuarios de drogas inyectables en el municipio de Florianópolis-SC. Se realizaron entrevistas utilizando la técnica de Historia Oral Temática. Los sujetos de estudio fueron diez profesionales de salud que ejercieron actividades de atención y/o gestión vinculadas a las ETS/SIDA en el período estudiado (1993-2010). Datos tratados por análisis de contenido, conformándose dos categorías: Implantación del Proyecto de Reducción de Deterioros en Florianópolis; y Reconocimiento de la Reducción de Deterioros como política estratégica de prevención del HIV y otras situaciones de vulnerabilidad. Como resultados, se destacan en este municipio, aspectos de esta política inclusiva e innovadora en el cuidado en salud, al poner en práctica principios sustantivos del SUS entre usuarios de drogas, generando nuevas posibilidades de prevención y cuidado entre esta población.

Descriptores: Síndrome de Inmunodeficiencia Adquirida; Consumidores de Drogas; Reducción del Daño. 


\section{INTRODUÇÃo}

Desde seu surgimento, a aids apresentou uma interface com o uso de drogas injetáveis, constituindo-se desde os primeiros anos da epidemia em uma importante via de transmissão do $\mathrm{HIV}^{(1)}$. O Brasil é um país que apresenta padrões de transmissão do vírus da aids diferenciados, de acordo com as regiões geográficas afetadas, compondo diversas sub-epidemias regionais. Neste contexto, a região Sul historicamente tem merecido destaque por concentrar altos índices da epidemia entre usuários de drogas injetáveis (UDI) e seus parceiros sexuais $^{(2)}$.

A problemática do uso de drogas passou a requerer maior atenção do sistema de saúde com o advento da aids, especialmente nos primeiros anos da epidemia no Brasil (1980-1993), quando a transmissão dos casos se deu em $27,9 \%$ pelo uso de drogas injetáveis. Em Santa Catarina, nos primeiros anos da epidemia (1984-1993), a transmissão do HIV entre UDI foi de 52\%. Na capital, Florianópolis, do período de 1986 a 1993, 56,3\% dos casos de aids foram transmitidos por esta mesma via de contaminação(3-4). Neste contexto, os UDI constituíram uma população especialmente vulnerável à infecção por HIV, caracterizada por sua invisibilidade, estereótipos e marginalização social, de difícil alcance para intervenções em saúde. O fato de esse grupo ter vida sexual ativa e, de modo geral, com múltiplas parcerias, contribuiu para enfatizar a importância de ações preventivas e uma maior divulgação dos mecanismos de prevenção das doenças de transmissão sexual e parenteral ${ }^{(5)}$.

Face ao preocupante padrão de transmissão do HIV observado no país, especialmente em algumas regiões, passaram-se a buscar estratégias de controle da epidemia nesta população, partindo de experiências internacionais que se mostravam exitosas. Deste modo, foram estruturadas diversas ações buscando diminuir a expansão da disseminação do HIV entre a população em geral e, mais diretamente, aos usuários de drogas injetáveis ${ }^{(2,6)}$. Neste contexto, a Redução de Danos (RD) entrou em cena no país, inicialmente como forma de abordar a prevenção do HIV entre usuários de drogas injetáveis.

A Redução de Danos é um movimento internacional que surgiu em resposta à crescente propagação da aids na década de 1980. As primeiras intervenções adotadas dentro deste referencial datam de 1926, na Inglaterra, através do relatório Rolleston, que estabelecia a possibilidade do médico prescrever opiáceos, legalmente, como forma de minimizar os efeitos mais danosos à saúde dos indivíduos que eram adictos a determinadas drogas que tinham o ópio como princípio ativo(7).

A Associação Internacional de Redução de Danos (IHRA) entende a RD como um conjunto de políticas, programas e práticas que visam primeiramente reduzir as consequências adversas para a saúde, resultantes do uso de drogas lícitas e ilícitas, sem necessariamente que a pessoa reduza o seu consumo. O princípio fundamental que orienta estas ações é o respeito à liberdade de escolha, visto que muitos usuários não conseguem ou não querem deixar de usar drogas, porém, necessitam ter os riscos decorrentes do seu uso minimizados ${ }^{(5,8)}$.

Antes de tornar-se uma estratégia de prevenção, a Redução de Danos deu-se como movimento político. A Holanda já vinha abordando esta temática no decorrer da década de 1970 através de sua legislação sobre drogas, e passou a adotar a troca de seringas de modo experimental em Amsterdã, no ano de 1984, a fim de prevenir a transmissão do vírus da hepatite $\mathrm{B}$. Ao se perceber que o HIV poderia ser transmitido pelo compartilhamento de agulhas contaminadas, estes programas voltaram-se principalmente para a prevenção da transmissão da aids $^{(7)}$. Essa abordagem ganhou notoriedade a partir do final da década de 1980 em alguns países europeus e da Austrália, se estendendo para outros países à medida que a infecção por HIV entre usuários de drogas injetáveis (UDI) foi adquirindo magnitude ${ }^{(9-10)}$.

Em 1994, o Ministério da Saúde assumiu a RD como estratégia de saúde pública para a prevenção das DST/Aids e hepatites entre usuários de drogas injetáveis, por meio de uma cooperação com o Programa das Nações Unidas para o Controle Internacional de Drogas, constituindo-se o primeiro projeto de RD apoiado por este organismo internacional. Até então, a primeira experiência em RD ocorrida no Brasil (na cidade de Santos-SP, em 1989) havia sido interrompida por uma interdição judicial, sendo reiniciada somente em 1995 na cidade de Salvador ${ }^{(6)}$. A partir destas iniciativas, a RD se desenvolveu no Brasil através dos Programas ou Projetos de Redução de Danos (PRD), contemplando uma série de ações desenvolvidas em campo, tais como: distribuição de seringas, atividades de informação, educação e comunicação, aconselhamento, encaminhamento, vacinação e outras ações preventivas ${ }^{(11)}$.

O município de Florianópolis-SC, formulou sua política de RD a partir da estruturação do Programa Municipal DST/Aids no ano de 1993, como forma de responder à epidemia de aids. Esta proposta, no entanto, causou impacto nos vários setores da sociedade local, por ter como princípio o respeito à autonomia do individuo frente 
ao uso de drogas, buscando instrumentalizá-lo para prevenção de doenças de contágio sanguíneo e/ou sexual.

Frente à amplitude do fenômeno do consumo de drogas no mundo contemporâneo, o debate teórico em torno da RD tem se ampliado, pois diante das contradições sociais e de saúde que envolvem o complexo sistema das drogas, a RD tem se constituido como um "movimento" político, tornando-se objeto de vários campos do saber, servindo de base para a ampliação do debate sobre as questões que envolvem o uso das substâncias psicoativas ${ }^{(12)}$.

Diante da complexidade que envolve a temática das drogas e a vulnerabilidade por ela produzida, incluindo aqui as doenças sexualmente transmissíveis, foi objetivo deste estudo analisar como a Política de Redução de Danos se desenvolveu enquanto estratégia de prevenção e cuidado entre os usuários de drogas injetáveis no município de Florianópolis-SC, buscando destacar a importância desta política no campo da saúde pública, apesar de todos os conflitos e confrontos envolvidos nesta estratégia, pois apesar de solidamente fundamentada, esta é ainda na atualidade alvo de críticas combativas ${ }^{(13)}$.

A retrospectiva histórica desta política se faz importante no sentido de compreender e dar visibilidade aos aspectos relevantes de políticas de saúde inclusivas, tal como a de RD, para a redução da vulnerabilidade de determinadas populações, em respeito aos direitos humanos à população de usuários de drogas, seus familiares e próximos ${ }^{(14)}$, além de difundir e estimular iniciativas desta natureza nos diversos contextos ${ }^{(15)}$. De forma estratégica, a perspectiva histórica assume o compromisso de dar visibilidade aos atores e elucidar os cenários em que a RD se desenvolveu, visando destacar o protagonismo desta política que se propõe a extrapolar os limites das práticas de saúde concebidas nos intramuros das instituições, indo ao encontro da realidade das ruas e das pessoas em situação de grandes adversidades ${ }^{(16)}$, visando resgatar um pouco de cidadania para esta população tradicionalmente excluída e marginalizada pelas políticas públicas.

\section{METODOLOGIA}

Trata-se de um estudo qualitativo de natureza sóciohistórica, que utilizou as bases filosóficas da nova história, onde se busca não apenas narrar os acontecimentos, mas analisar as estruturas. Esta perspectiva busca compreender a repercussão política de uma manifestação social, dando voz a história vinda de pessoas anônimas, comuns, e do cotidiano(17). O contexto deste estudo foi a Secretaria Municipal de Saúde de Florianópolis e
Desenvolvimento Social (SMSDSF). O recorte histórico se deu a partir de 1993, ano que se inicia a estruturação oficial do Programa DST/Aids de Florianópolis e o ponto de corte foi o ano de 2010, quando a Estratégia de Redução de Danos passou a ser vinculada ao Centro de Atenção Psicossocial Álcool e Drogas (CAPS AD).

Os sujeitos do estudo foram 10 profissionais de saúde, dentre eles quatro enfermeiras, quatro médicos e duas psicólogas, que atenderam aos seguintes critérios: ter atuado no Programa DST/Aids e/ou Programa Redução de Danos em algum momento do período histórico estudado (1986-2010), poder contribuir com os objetivos do estudo, e estar disposto a participar da pesquisa. Por se tratar de um estudo com uma perspectiva histórica, as entrevistas foram formuladas a partir da História Oral Temática. A história oral temática é um método de pesquisa que privilegia a realização de entrevistas com pessoas que participaram ou testemunharam acontecimentos, sendo esta uma forma de aproximação do objeto de estudo. Através deste método pode-se estudar acontecimentos históricos, grupos sociais, categorias profissionais, movimentos, conjunturas ${ }^{(17)}$.

A escolha dos sujeitos e ordem de entrevista seguiu como critério inicial a temporalidade, iniciando pela primeira coordenadora do Programa Municipal de Controle de DST/Aids, oficializado em 1993, sendo esta entrevista denominada ponto zero(17), seguindo os demais sujeitos que passaram a atuar no programa posteriormente. Embora em uma pesquisa histórica que utiliza como recurso a história oral, a identificação dos sujeitos seja considerada, mantivemos o anonimato dos mesmos neste estudo pelo próprio desejo da maioria deles. Deste modo, os sujeitos estão identificados por letras, de forma que para os enfermeiros a sequência se dá de E1 a E4, seguindo-se a ordem cronológica que estes profissionais participaram do programa, os médicos estão classificados na ordem de M1 a M4, e psicólogos como P1 e P2. O período de coleta dos dados ocorreu entre julho de 2010 a janeiro de 2012. As entrevistas foram gravadas em gravador digital, com a autorização dos participantes.

Para a realização deste estudo, foram observados todos os princípios éticos de pesquisa com seres humanos, de acordo com a Resolução 466/12 do Conselho Nacional de Saúde ${ }^{(18)}$. Após esclarecimento dos objetivos da pesquisa e leitura do Termo de Consentimento Livre e Esclarecido (TCLE), os sujeitos autorizaram sua participação no estudo assinando o TCLE em duas vias, sendo que uma ficou de posse da pesquisadora, e outra com o próprio sujeito. Este estudo foi submetido à apreciação do Comitê de Ética e Pesquisa com Seres 
Humanos da Universidade Federal de Santa Catarina, sendo aprovado por meio do parecer no 592, de 22 de Fevereiro de 2010.

Para o tratamento dos dados, o conteúdo das entrevistas passou inicialmente por um processo de transcrição, partindo do referencial de Meihy ${ }^{(17)}$, incluindo a textualização, transcriação, e conferência. De acordo com o autor, a textualização corresponde a definição de palavras-chave e o estabelecimento de ideias contidas no texto, a transcriação corresponde a finalização do texto em sua versão pronta, retirando-se todas as expressões de uso coloquial, repetições e inferências desnecessárias, e a conferência se refere a avaliação da versão final da entrevista pelo entrevistado para autorização de seu conteúdo. Dado este processo, o tratamento dos dados seguiu a análise de conteúdo de $\operatorname{Bardin}^{(19)}$, tendo-se como primeiro critério de organização dos conteúdos pela ordem temporal, sendo firmadas diversas delimitações relacionando tempo e fatos importantes. Em seguida, passou-se a classificar as unidades de análise previamente selecionadas (palavras-chave), iniciando o agrupamento das semelhanças, constituição das subcategorias de análise; reagrupamento das subcategorias de análise, chegando as seguintes categorias: A implantação do Projeto de Redução de Danos em Florianópolis; e O reconhecimento da Redução de Danos como política estratégica de prevenção ao HIV e outras situações de vulnerabilidade.

\section{RESULTADOS E DISCUSSÃO}

\section{A implantação do Projeto de Redução de Danos em Florianópolis}

A introdução deste tema no âmbito do governo municipal ocorreu no Primeiro Seminário Nacional de Prevenção ao HIV/Aids entre UDIs, realizado de 30 de junho a 02 de julho de 1993, em Florianópolis, reunindo autoridades em saúde das esferas federal, estaduais e municipais, do representante no Brasil do Programa das Nações Unidas para o Controle Internacional de Drogas, representantes de Organizações não Governamentais, profissionais de saúde, entre outros. Neste seminário se discutiu a gravidade da transmissão do HIV por uso de drogas injetáveis no Brasil, a experiência de Programas de Redução de Danos em alguns países, e a necessidade de se criar estratégias no país para reduzir a transmissão do HIV entre usuários de drogas injetáveis ${ }^{(20)}$.

No evento, destacou-se o panorama dos casos de aids em Santa Catarina, sendo ressaltadas características diferenciais da epidemia ao serem observados os primeiros registros da transmissão do HIV por uso de drogas injetáveis, além de maior incursão da epidemia em cidades portuárias, centros turísticos e industriais. Até o ano do seminário, já haviam sido registrados 825 casos de aids no estado, com uma mortalidade de $42,5 \%$ dos casos. Ao ser apresentadas as categorias de transmissão do HIV no estado, e o destaque para o uso de drogas injetáveis, como principal categoria de transmissão $(43,8 \%)$ muitos profissionais de saúde foram surpreendidos com a informação, pois:

A questão do HIV entre usuários de drogas injetáveis que para nós era uma incógnita, e quando foram mostrados os dados que chegaram a Brasília, mas que eu não tinha conhecimento eu fiquei de queixo caído, não pelo número absoluto, mas pela incidência, mas Florianópolis já tava demonstrando uma maior proporção de casos em UDI, eram bem maiores que em qualquer outra categoria, $e$ aqui se falava muito na transmissão por relações homossexuais, e a coisa era o contrário (E1).

O desconhecimento dos profissionais do município de Florianópolis a respeito do perfil epidemiológico da epidemia em seu próprio território se deve, principalmente, pelo modo como o sistema de saúde estava organizado na época. O município teve estruturado oficialmente o Programa Municipal DST/Aids apenas em 1993, ficando até então a maior parte das ações relacionadas a aids concentradas na esfera estadual e federal, o que repercutia inclusive no entrave do fluxo de informações relacionados a epidemia.

O Programa Municipal DST/Aids do município de Florianópolis, ao estruturar-se a partir do ano de 1993, tendo conhecimento das altas incidências na cidade em relação a esta categoria de transmissão, passou a buscar alternativas para se aproximar destas populações de risco e conhecer sua própria dinâmica, a fim de estabelecer estratégias de intervenção:

Quando nós começamos a pensar em projeto redução de danos e eles foram pensados não apenas de cima para baixo, mas porque nós fizemos um projeto muito bacana de planejamento local, territorialização, nós fizemos um levantamento de problemas com a comunidade e em muitos locais a prioridade era: controlar a drogadição, o tráfico de drogas, tinha toda uma proposta de integração com a rede de saúde, com todas essas demandas (M1).

A RD envolveu muita polêmica desde as primeiras discussões no Brasil. A legislação em vigor no início da 
década de 90, ainda apoiada na lei No 6368/76 (que dispõe sobre medidas de prevenção e repressão ao tráfico ilícito e uso indevido de substâncias entorpecentes ou que determinem dependência física ou psíquica), proporcionou interpretações contrárias à prática de RD, por considerar a distribuição de seringas como auxílio ou incentivo ao uso de drogas ${ }^{(6)}$. Estas divergências repercutiram também em Florianópolis, quando esta prática passou a ser pensada no município:

Nós começamos a fazer algumas ações, que inclusive fizeram na época um encontro estadual e me convidaram e quando eu disse que as ações da prefeitura eram no sentido de reduzir os danos, com um perfil epidemiológico fortemente concentrado em usuários de drogas, um policial se levantou e disse que era para eu me cuidar, era um encontro na secretaria de justiça, que mais uma colocação que eu fizesse nesse sentido eu estaria sendo enquadrado como incitamento ao tráfico de drogas. A briga era nesse sentido, posições muito firmes, cada um do seu lado, não havia uma possibilidade de negociação, que na verdade se tentava, mas as posturas eram muito rigorosas (M2).

A RD foi interpretada inicialmente como incitamento ao uso de drogas ilícitas e, portanto, passível de punição. A difícil compreensão sobre a RD foi, muitas vezes, o principal foco da discussão, já que a RD não incentiva o uso de drogas, mas reconhece que existem danos e consequências envolvidas. A abstinência não é rejeitada, mas se considera a necessidade de implementar estratégias realistas e pragmáticas, reconhecendo-se o grau de liberdade e corresponsabilidade do indivíduo em questão(21).

À medida que o tema foi sendo debatido e polemizado, cresceu entre os profissionais e gestores a percepção de que a RD seria possível não pela imposição, mas pela compreensão de um novo paradigma. A diferença deste paradigma consiste em reconhecer a autonomia de cada cidadão, bem como dos direitos garantidos pela própria constituição que prevê, no artigo 196, a "promoção de políticas que visem a redução do risco de doença, bem como acesso igualitário as ações de promoção, proteção e recuperação a saúde"(22).

O Programa Municipal DST/Aids de Florianópolis, ao se estruturar a partir de 1993 , elaborou suas propostas reconhecendo as altas incidências em relação a categoria de transmissão por uso de drogas injetáveis. Com isso, passou a buscar alternativas para se aproximar destas populações de risco e conhecer sua própria dinâmica, a fim de estabelecer estratégias de intervenção:

A gente ia fazer oficinas, em comunidades onde a gente via a questão da prevalência do HIV [...] a gente subiu o Morro (...) para conversar com pessoas que vendiam drogas, toda essa questão do uso injetável, o que eles achavam de ajudar essa questão do não compartilhamento [...] (E3).

Era necessário conhecer as populações mais atingidas pela epidemia, especialmente onde se evidenciava a prática do uso de drogas injetáveis, pois no início da epidemia pouco se sabia a respeito dos UDIs. Esta era uma população desconhecida para os serviços de saúde, de forma geral economicamente desfavorecida, marcada por uma estratégia policial-repressiva de criminalização do usuário de drogas ${ }^{(20)}$.

Do período de 1994 a 1997, diversos treinamentos e oficinas foram realizados em Florianópolis abordando a temática da RD, com a participação de profissionais da rede municipal de saúde e membros do Conselho Municipal e Estadual de Entorpecentes. No entanto, a oficialização desta proposta foi firmada pela assinatura de convênio entre a SMSDSF e Ministério da Saúde, no primeiro semestre de 1997 , oficializado inicialmente na forma de projeto. A partir do convênio, uma organização não governamental selecionou quatro agentes para fazer o reconhecimento dos campos (locais em que se concentravam usuários de drogas injetáveis). As atividades iniciaram efetivamente em janeiro de 1998, por meio de um trabalho educativo entre os UDIs e comunidades, distribuição de material educativo, preservativos e materiais para injeção estéril(23).

Posteriormente, a SMSDSF assinou um convênio com o Instituto Arco-Íris de Prevenção a Aids (Convênio No 112/99), assumindo o pagamento de recursos humanos da equipe, que até então era feito com recursos do Banco Internacional para Reconstrução e Desenvolvimento (BIRD) $^{(23)}$. Cabe salientar que, mesmo antes da atuação oficial das equipes de RD em Florianópolis, alguns profissionais de centros de saúde de comunidades com alta prevalência de UDIs, forneciam seringas e agulhas aos usuários de maneira informal, movidos por um sentimento de solidariedade e respeito ao direito de escolha de cada um. No entanto, a oficialização desta proposta permitiu aos usuários de drogas injetáveis a entrada no cenário das políticas públicas de saúde, tornando-os importantes agentes nas estratégias de prevenção da aids ${ }^{(20)}$.

Ainda nesse período, a Lei Estadual No 11.063, de 28 
de dezembro de 1998, autorizou a Secretaria de Estado da Saúde a distribuir seringas descartáveis aos usuários de drogas, legitimando a criação de projetos de RD no Estado(23). Deste modo, apesar das manifestações polêmicas e da rejeição inicial, a RD foi se inserindo a política de saúde do município de forma processual, sendo gradualmente compreendida pelos profissionais de saúde e sociedade local:

Tinha uma serie de empecilhos, mas eu acho que foi um dos projetos que foi bem sucedido, teve adesão das pessoas das comunidades para trabalhar, teve liberdade de contratação de pessoas capacitadas ou que tinham um vinculo já com a comunidade, isso facilitou bastante [...] era tudo muito novo então as pessoas tinham um certo receio, foi indo e acabou se vendo que não tinha nada a ver com o trafico, o que a gente queria era fazer saúde (E2).

Em avaliação preliminar da coordenação do Programa Municipal DST/Aids, juntamente com a equipe de RD após o primeiro ano de atividade, os usuários abordados por este projeto mostraram-se sensíveis a esta estratégia. À medida que alcançavam novos usuários, foram observadas mudanças de comportamento, como destino adequado do material já utilizado e aumento da demanda para o tratamento da drogadição. $\mathrm{Na}$ avaliação, as dificuldades apontadas incluíram a falta de serviços públicos destinados aos usuários que quisessem tratamento e o preconceito ainda existente de alguns profissionais de saúde em relação aos UDIs ${ }^{(20)}$.

\section{O reconhecimento da Redução de Danos como política estratégica de prevenção ao HIV e outras situações de vulnerabilidade}

Embora o Ministério da Saúde tenha reconhecido a RD como estratégia de intervenção em 1994, a aceitação e implementação no país ocorreu de forma diferenciada e gradativa. Esta proposta foi ganhando força à medida que foi sendo integrada às políticas nacionais relacionadas ao fenômeno das drogas.

No ano de 2001, o texto da Lei 10.216, que trata do marco legal da Reforma Psiquiátrica, destacou de forma histórica, as diretrizes básicas que constituem o Sistema Único de Saúde, garantindo aos usuários de serviços de saúde mental e aqueles que sofrem por transtornos decorrentes do consumo de álcool e outras drogas - a universalidade de acesso e direito à assistência, a integralidade e descentralização do modelo de atenção. Para tanto, foram propostos diversos mecanismos, dentre eles a adoção de uma lógica ampliada de RD, realizando uma procura ativa e sistemática das necessidades a serem atendidas, de forma integrada, ao meio cultural e à comunidade em que estão inseridos ${ }^{(21)}$.

O Ministério da Saúde instituiu a Política para a Atenção Integral ao Uso de Álcool e Outras Drogas no ano de 2003, reafirmando o uso de álcool e outras drogas como grave problema de saúde pública, e reconhecendo a necessidade de assumir esta responsabilidade através do Sistema Único de Saúde (SUS), com vistas a subsidiar uma construção coletiva para o seu enfrentamento. Esta política passou a preconizar a assistência aos UDIs em todos os níveis de atenção, especialmente nos CAPS AD. Em 2005, a RD se constituiu em um dos eixos da Política Nacional Sobre Drogas, aprovada pelo Conselho Nacional Antidrogas (CONAD). Os outros eixos, também de importância fundamental, são: Prevenção; Tratamento, Recuperação e Reinserção Social; Redução da Oferta; e Estudos, Pesquisas e Avaliações ${ }^{(21)}$.

Com o avanço das discussões em torno da RD, as formas do uso da droga também sofreram modificações. A partir da década de 90, registrou-se um crescente consumo do crack, e indicativos da migração de usuários de cocaína injetável para esta droga ${ }^{(2,24)}$. Neste sentido, a preocupação em torno da RD foi ampliada tanto para outras drogas, quanto para outras formas de uso:

O programa de redução de danos trabalhava bastante com essa questão de usuários, principalmente de injetáveis, mas também estava se percebendo que a questão do crack é muito mais importante do que a discussão dos injetáveis, então estava se começando a discussão sobre protetores labiais, cachimbo, enfim, outras formas de se trabalhar com os usuários de droga. E estavam trabalhando integrado a discussão do álcool também como sendo um outro fator de vulnerabilidade para a exposição (M4).

A abordagem da Saúde Pública voltada para os usuários de álcool e outras drogas foi reformulada a partir dos avanços promovidos pela Reforma Psiquiátrica e pela Reforma Sanitária, passando-se a dar maior visibilidade ao usuário portador de transtorno mental e/ou toxicômano. Neste sentido, os serviços de saúde buscaram diversificar as modalidades de atendimento, objetivos e direção dos tratamentos, em compasso com os princípios e as diretrizes do SUS ${ }^{(10)}$.

Frente a estas tendências, a RD passou a ser entendida não mais como um projeto pontual, mas como uma estratégia de múltiplas possibilidades, apresentando 
como uma alternativa no campo das práticas de saúde relacionadas aos problemas com o consumo de drogas, visando resgatar aspectos éticos e humanos da relação entre políticas de saúde e consumidores de drogas ${ }^{(12)}$.

Neste contexto, a RD passou a ter como proposta, a integração desta estratégia junto à Saúde Mental e à Saúde da Família na Atenção Básica, abordando pessoas, famílias, grupos e instituições em sua integralidade(10). Esta tendência teve repercussões no município de Florianópolis, que integrou a RD como estratégia junto ao Programa Municipal de Saúde Mental:

A prefeitura, dentro do quadro da coordenação de aids, tinha o Projeto Redução de Danos que se transformou em estratégia e hoje, esta vinculada administrativamente aos CAPS AD (Centros de Atenção Psicossocial a Usuários de Álcool e outras Drogas). [...] Em 2007 a Redução de Danos foi pactuada com o CAPS e com a Saúde Mental, com o objetivo que a Redução de Danos ficasse mais próxima dos usuários, também trabalhar o vinculo e atividades de grupo com esses usuários, e não só fazer trabalho de campo. E hoje o Ministério incentiva e preconiza que a estratégia de ação do CAPS se paute pela Redução de Danos (P1).

Assim, desde o início dos anos 2000, a integração da Redução de Danos ao Programa de Saúde Mental do município tornou-se uma realidade em potencial, materializando-se a partir de 2007, visto que o primeiro CAPS AD iniciou suas atividades em 2006, e o segundo CAPS AD em 2010:

Hoje está fortemente vinculado ao CAPS. Na verdade o movimento foi esse, do programa ir se integrando as coisas que passaram a existir, quando o município começou a se estruturar melhor, a existir na média complexidade, o programa foi vendo as formas de se relacionar e construir as pontes entre esses serviços, até porque já se trabalhava bastante com essa questão de álcool e de orientação, de prevenção, dentro do programa de redução de danos (M3).

A integração de ações de RD no campo da saúde pública ainda é um caminho em construção, dada sua recente integração aos CAPS $A D^{(14)}$, atuais dispositivos de cuidado para a população de usuários de drogas, embora estejam em número muito aquém da necessidade em nosso país ${ }^{(16)}$.

Vale ressaltar que a estruturação da equipe de RD sofreu mudanças ao longo do tempo. Em 1998, o trabalho foi iniciado através de uma parceria entre uma organização da sociedade civil e a SMSDSF. Em 2005, a gestão municipal assumiu a RD como ação própria, e a equipe passou a ser vinculada a Associação Florianopolitana de Voluntários, trazendo benefícios trabalhistas aos profissionais vinculados. No entanto, a inexistência do cargo de "redutor de danos" impossibilitou a efetivação do profissional junto ao quadro de recursos humanos da SMSDSF, mantendo a equipe em uma situação de instabilidade, dependendo da renovação de convênios anuais para sua manutenção.

Apesar da fragilidade da proposta no que diz respeito à política de recursos humanos, a RD passou por um processo de reorientação, em que o foco de atenção da estratégia deixou de ser apenas a transmissão do HIV, ampliando-a com a inclusão dos agravos sociais e de saúde que esta população vulnerável está exposta:

O programa de redução de danos acabou tendo destaque porque eles [a equipe] são os agentes comunitários de saúde da população de rua. Essa foi a analogia que se criou e que o pessoal entendeu bem, porque eram eles que sabiam aonde é que essas pessoas acabavam circulando, quando elas saiam de um determinado lugar e acabavam indo para um outro lugar e saiam de um morro e iam para outro morro. Muitas vezes só se conseguia resgatar essa pessoa para o serviço por intermédio da redução de danos. Então, a partir do momento que eles perderam essa coisa de estou preocupado com a aids e começaram a se preocupar com as pessoas que estavam com risco de aids, eles se deram conta que elas estavam com risco de outras coisas também. Eu acho que essa aproximação com o CAPS ajudou bastante (P2).

As ações de RD deram visibilidade, inicialmente, aos UDIs no SUS, como estratégia para a formação de vínculos com esta população que se encontra à margem da sociedade e dos serviços de saúde. As interações ocorriam por meio do oferecimento de insumos e de orientações para prevenção de doenças transmissíveis e outros agravos à saúde, como forma de viabilizar a atenção à saúde e promover o reconhecimento de direitos sociais desse grupo em particular. Esta política contribuiu para a organização de profissionais, como de usuários, dando importantes contribuições para a revisão das leis até então em vigor, proporcionando o compartilhamento de saberes e criando condições para a construção de estratégias eficazes na abordagem dos problemas de saúde dos consumidores de drogas ${ }^{(10,24)}$. 
Desde a segunda metade da década de 1990, registros epidemiológicos ${ }^{(22)}$ mostram um decréscimo contínuo na transmissão do HIV pelo uso de drogas injetáveis em todas as regiões do Brasil, e aumento da transmissão heterossexual. Como ilustração, do período de 2007-2011 no Brasil, entre os casos de aids diagnosticados, a proporção de UDI no país foi de 3,15\%, em Santa Catarina foi de 5,72\%, e em Florianópolis $8,15 \%{ }^{(3)}$, revelando uma importante redução da transmissão do HIV por contaminação parenteral, quando comparada ao início da epidemia. Este fato vem sendo relacionado, dentre outros fatores, à política de $\mathrm{RD}$ adotada no Brasil, a mudança do comportamento dos UDIs, com adoção de práticas mais seguras; e à mudança no perfil de uso de drogas, seja a migração para o uso de outras drogas ou outras formas de uso(2).

Neste sentido, observa-se que o controle da epidemia no Brasil torna-se mais efetivo quando as políticas públicas são desenhadas conforme os perfis locais, reforçando a responsabilidade dos municípios na organização da rede de atenção e promoção da saúde ${ }^{(25)}$. Estes fatos legitimam o trabalho da RD no país, apontando para a necessidade de investimento e ampliação de políticas dessa natureza, e para a manutenção e ampliação do acesso aos serviços de saúde a este grupo populacional.

\section{CONSIDERAÇÕES FINAIS}

A Redução de Danos foi concebida como importante estratégia de prevenção entre usuários de drogas, constituindo-se em um dos pilares do Programa Municipal DST/Aids em Florianópolis, desenvolvido por uma equipe multiprofissional. A rejeição inicial da proposta foi identificada em diversos setores da sociedade, suscitando conflitos de distintas dimensões. Porém, mesmo frente às controvérsias iniciais, houve o reconhecimento deste problema de saúde pública no município, relacionado ao uso de drogas. Aliada à complexa trama que envolve o tema, cresceu entre os atores sociais a percepção sobre a necessidade de inclusão dos usuários de drogas no sistema de saúde, de modo a promover maior visibilidade para esta população, até então concebida pela ótica da criminalidade.

A perspectiva da Redução de Danos foi ampliando-se para incluir também respostas a outros padrões do consumo de drogas lícitas e ilícitas, e compreender o usuário de drogas não apenas como sujeito vulnerável a aids, mas as demais situações sociais e de saúde produzidas por sua própria condição de vulnerabilidade. Deste modo, esta política foi sedimentada no sistema municipal de saúde, inicialmente como projeto e posteriormente como estratégia, extrapolando o campo de ação das DST/Aids, e integrando-se a Política de Saúde Mental do município. Uma das fragilidades, diz respeito ao próprio vínculo institucional da equipe, visto que a mesma não compõe o quadro de recursos humanos da SMSDSF e depende da renovação de convênios anuais e de um constante trabalho de convencimento junto aos gestores para assegurar sua manutenção.

Ao trazer ao leitor uma perspectiva histórica da política de RD em Florianópolis, além de cumprir um objetivo investigativo, destacam-se relevantes aspectos desta política inclusiva e inovadora no cuidado em saúde, especialmente ao colocar em prática princípios substantivos do SUS entre usuários de drogas: de universalidade, levando o sistema de saúde ao lócus do usuário; equidade, oferecendo uma alternativa para a redução da demanda das drogas, ao tempo em que respeita o direito da liberdade de escolha de cada indivíduo; de integralidade, promovendo diferentes medidas de prevenção com relação a aids, hepatites e demais DSTs, ou co-infecções que produzem complicações em indivíduos já infectados por estas morbidades.

Cabe destacar, neste contexto, o protagonismo de profissionais de saúde que 'abraçaram' a causa da RD, dentre eles de enfermeiras que participaram da formulação e implementação desta política municipal, enfrentando inúmeras resistências, tendo em vista que a RD mostrou-se como uma proposta impactante, por ter como princípio o respeito à autonomia do individuo frente ao uso de drogas, buscando instrumentalizá-lo para prevenção de doenças de contágio sanguíneo e/ou sexual.

Entre usuários de drogas, a Redução de Danos contemplou a população de rua, excluída e vulnerável, exposta a violência e outras mazelas sociais, revelandose como uma importante política de inclusão. No entanto, é necessário reconhecer que o padrão de transmissão por HIV por uso da droga injetável continua recebendo destaque no cenário nacional, tornando-se necessário pensar políticas públicas intersetoriais que possam ampliar as respostas a este fenômeno.

Contudo, em relação à assistência a esta população, algumas dificuldades são evidentes, visto que as instituições de tratamento para dependência as drogas são ainda restritas no âmbito do SUS, dificultando o acesso ao usuário que deseja se tratar. Outra questão que merece destaque e atenção para estudos futuros, é a inserção desta política junto aos CAPS $A D$, ainda incipientes no país, passando-se a buscar o entendimento 
da RD como uma estratégia ampliada de atenção, no sentido de responder as várias vulnerabilidades encontradas entre a população.

\section{REFERÊNCIAS}

1. Vlahov D, Celentano DD. Access to highly active antiretroviral therapy for injection drug users: adherence, resistance, and death. Cad. Saúde Pública [Internet]. 2006 [cited 2012 abr 01]; 22(4): 705-718. Available from: http://www.scielo.br/scielo.php?script=sci_arttext\&pid=S0102311X2006000400002\&lng=en.

2. Caiaffa WT et al. The contribution of two Brazilian multi-center studies to the assessment of HIV and HCV infection and prevention strategies among injecting drug users: the AjUDEBrasil I and II Projects. Cad Saúde Pública [Internet] 2006 [cited 2011 se 23$]$; 22:771-782. Available from:

http://www.scielo.br/scielo.php?script=sci_arttext\&pid=S0102$311 \times 2006000400016 \&$ Ing $=$ en\&nrm =iso.

3. Ministério da Saúde. Departamento de Informática do SUS. Informações em Saúde. Epidemiológicas e Morbidade. Casos de aids identificados no Brasil. Freqüência por Categ Exp Hierar segundo Ano Notificação. Período: 1980,1982-2011. [Internet] 2011 [cited 2011 set 23]; Available from:

http://www2.aids.gov.br/cgi/tabcgi.exe?tabnet/br.def.

4. Secretaria de Estado da Saúde (Santa Catarina). Diretoria de Vigilância Epidemiológica. Banco de Dados do SINANW - Sistema Nacional de Agravos de Notificação. Casos de Aids em adultos e crianças segundo categoria de exposição e ano de diagnóstico, município de Florianópolis, 1986-2011. Florianópolis, 2011. 5. Marchesini AM, Prá-Baldi ZP, Mesquita F, Bueno R, Buchalla $\mathrm{CM}$. Hepatites $\mathrm{B}$ e $\mathrm{C}$ em usuários de drogas injetáveis vivendo com HIV em São Paulo, Brasil. Rev. Saúde Pública [Internet]. 2007 [cited 2012 jul 18]; 41 (2): 57-63. Available from: http://www.scielo.br/scielo.php?script=sci arttext\&pid=S003489102007000900010\&lng=en\&nrm=iso.

6. Marques F, Doneda DA. A política brasileira de redução de danos à saúde pelo uso indevido de drogas: diretrizes e seus desdobramentos nos Estados e Municípios. In: Bastos FI, Mesquita F, Marques LF(Orgs.) Troca de seringas: drogas e Aids. Brasília: Ministério da Saúde; 1998.

7. Queiroz IS. Os programas de redução de danos como espaços de exercício da cidadania dos usuários de drogas. Psicol. cienc. prof. $2001 ; 21$ (4):

8. Associação Internacional de Redução de Danos (IHRA). O que é redução de danos? Uma posição oficial da Associação Internacional de Redução de Danos, Londres, Grã Bretanha [Internet]. 2010 [cited 2011 ago 23] Available from: <http://www.ihra.net/files/2010/06/01/Briefing_what_is_HR_Por tuguese.pdf $>$.

9. Telles PR, Bastos FI. Estratégias da redução de danos In: Ministério da Saúde. Secretaria de Assistência à Saúde.

Coordenação-Geral de Doenças Sexualmente

Transmissíveis/Aids. Drogas, Aids e Sociedade. Brasília: Centro de Documentação Informação e Comunicação; 1995.

10. Conte M. Psicanálise e redução de danos: articulações possíveis? Revista da Associação Psicanalítica de Porto Alegre [Internet] 2004 [cited 2011 ago 16]; (26):23-33. Available from: http://www.appoa.com.br/download/Revista\%2026\%20\%20Psican $\%$ E1lise $\% 20$ e $\% 20$ redu $\% E 7 \%$ A6o\%20de\%20danos.pd f

11. Souza KM, Monteiro S. A abordagem de redução de danos em espaços educativos não formais: um estudo qualitativo no estado do Rio de Janeiro, Brasil. Interface (Botucatu). 2011; 15(38):833-844.

12. Santos VE, Soares CB, Campos CMS. Redução de danos: análise das concepções que orientam as práticas no Brasil. Physis. 2010; 20(3):995-1015.

13. Adade M, Monteiro S. Educação sobre drogas: uma proposta orientada pela redução de danos. Educ. Pesqui. 2013, no.ahead, p.0-0.
14. Elias LA, Bastos FI.Saúde pública, redução de danos e a prevenção das infecções de transmissão sexual e sanguínea: revisão dos principais conceitos e sua implementação no Brasil. Ciênc. saúde coletiva. 2011; 16(12):4721-4730

15. Souza LM, Pinto MG. Atuação do enfermeiro a usuários de álcool e de outras drogas na Saúde da Família. Rev. Eletr. Enf. [Internet]. 2012 [cited 2012 ago 23] abr/jun;14(2):374-83. Available from:

http://www.fen.ufg.br/revista/v14/n2/v14n2a18.htm.

16. Andrade TM. Reflexões sobre políticas de drogas no Brasil. Ciênc. saúde coletiva 2011; 16(12):4665-4674.

17. Meihy JCSB. Manual de história oral. 2. ed. São Paulo: Loyola; 1998.

18. Resolução CNS No 466, de 12 de dezembro de 2012. Aprova as seguintes diretrizes e normas regulamentadoras de pesquisas envolvendo seres humanos. [cited 2013 nov 10]. Available from http://conselho.saude.gov.br/resolucoes/2012/Reso466.pdf 19. Bardin L. Análise de conteúdo. Lisboa; Edições 70, 2006. 20. Lago MA. Da marginalidade a tolerância: reflexões éticas sobre a estratégia de redução de danos. [dissertation]. Florianópolis: Mestrado em Saúde Pública/UFSC; 1999. 119 p. 21. Secretaria Nacional de Políticas sobre Drogas. Legislação e Políticas Públicas sobre Drogas. Brasília; 2010 [cited 2012 abr 01]. Available from:

http://www.brasil.gov.br/enfrentandoocrack/publicacoes/materia l-informativo/serie-por-dentro-do-assunto/legislacao-e-politicaspublicas-sobre-drogas-no-brasil

22. Constituição da República Federativa do Brasil [Internet] Texto Promulgado em 05 de outubro de 1988. [cited 2009 ago 14] Available from:

<http://www.senado.gov.br/sf/legislacao/const/

23. Secretaria Municipal de Saúde de Florianópolis. Projeto Institucional Redução de Danos em Usuários de Drogas. Sobre a importância da Estratégia de Redução de Danos. Florianópolis: Secretaria Municipal da Saúde; 2003.

24. De Boni RB et al. Diferenças entre fatores de risco para infecção pelo HIV em usuários de drogas injetáveis do Rio de Janeiro e Porto Alegre. Rev. psiquiatr. clín.[internet]. 2005; 32(1):5-9 [cited 2011 ago 31] Available from http://www.scielo.br/scielo.php?script=sci arttext\&pid=S010160832005000100001\&lng =pt\&nrm=iso.

25. Grangeiro A, Escuder MML, Castilho EA. Magnitude e tendência da epidemia de Aids em municípios brasileiros de 2002-2006. Rev. Saúde Pública [Internet]. 2010; 44 (3): 430441. [cited 2012 mai 2011]. Available from: http://www.scielo.br/scielo.php?script=sci_arttext\&pid=S0034$\underline{89102010000300006 \& \text { lng }=\text { pt\&nrm }=\text { iso. }}$.

Artigo recebido em 22/10/12 Aprovado para publicação em 06/11/13. Artigo publicado em 31/03/2014. 